\title{
After the smoke has cleared: Extended low fruit productivity following forest fires decreased gregariousness and social tolerance among wild female Bornean orangutans (Pongo pygmaeus wurmbii)
}

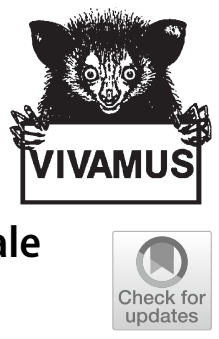

\author{
Alison M. Ashbury ${ }^{1,2,3}$ - Jade Meric de Bellefon ${ }^{1}$ - Julia A. Kunz ${ }^{1}$. \\ Misdi Abdullah ${ }^{4} \cdot$ Anna M. Marzec ${ }^{1}$. Caroline Fryns ${ }^{1,5} \cdot$ Sri Suci Utami Atmoko ${ }^{4}$. \\ Carel P. van Schaik ${ }^{1,6,7} \cdot$ Maria A. van Noordwijk ${ }^{1,7}$
}

Received: 21 May 2021 / Accepted: 5 October 2021 / Published online: 20 December 2021

(c) The Author(s) 2021

\begin{abstract}
As climate change continues to fundamentally alter resource landscapes, the ability to flexibly respond to spatio-temporal changes in the distribution of preferred food sources is increasingly important for the overall health and fitness of animals living in seasonal, variable, and/or changing environments. Here, we investigate the effects of an uncharacteristically long period of fruit scarcity, following widespread thick haze caused by peat and forest fires in 2015 , on the behaviour and sociality of female Bornean orangutans (Pongo pygmaeus wurmbii). We collected data from 2010 to 2018 at Tuanan, Central Kalimantan, Indonesia, and compared the activity, diet, and association patterns of adult females during low-fruit periods before the fires, i.e., regular, seasonal periods of low fruit availability ("pre-fire"), and after the fires, i.e., during the extended period of low fruit availability ("post-fire"). First, we found that, post-fire, female orangutans adopted a more extreme energy-saving activity pattern and diet resting more, travelling less, and diet-switching to less-preferred foods - compared to pre-fire. Second, we found that the probabilities of association between females and their weaned immature offspring, and between related and unrelated adult females were lower, and the probability of agonism between unrelated females was higher, post-fire than pre-fire. This change in energetic strategy, and the general reduction in gregariousness and social tolerance, demonstrates how forest fires can have lasting consequences for orangutans. Fission-fusion species such as orangutans can mitigate the effects of changes in resource landscapes by altering their (sub)grouping patterns; however, this may have long-term indirect consequences on their fitness.
\end{abstract}

Keywords Day journey length $\cdot$ Fallback foods $\cdot$ Fruit scarcity $\cdot$ Social patterns · Climate change $\cdot$ Female-female competition

Handling Editor: Joanna Setchell

Extended author information available on the last page of the article 


\section{Introduction}

The ability to flexibly respond to changes in the spatial and temporal distribution of preferred food sources is crucial for the overall health and fitness of many animals living in seasonal or highly variable environments (van Schaik \& Brockman, 2005). When important resources are scarce, animals can employ a range of behavioral strategies, such as diet-switching to lower-quality fallback foods, altering their ranging patterns to exploit alternative areas or resources, and/or altering their activity budgets to conserve energy (van Schaik \& Brockman, 2005; Marshall \& Wrangham, 2007).

Animal taxa that exhibit fission-fusion social dynamics can, additionally, respond to fluctuations in the spatio-temporal availability of resources by altering their subgrouping patterns (Sueur et al., 2011). For instance, seasonal scarcity in preferred resources can lead to a reduction in subgroup sizes and/or the frequency of associations, thus mitigating direct contest competition between conspecifics (e.g., ruffed lemurs, Varecia variegata, Baden et al., 2016; spider monkeys, Ateles geoffroyi, Aguilar-Melo et al., 2018, 2020; chimpanzees, Pan troglodytes, Doran, 1997; Matsumoto-Oda et al., 1998; hyenas, Crocuta crocuta, Smith et al., 2008; giraffes, Giraffa camelopardalis tippelskirchii, Bond et al., 2019). The energetic benefits of a reduction in sociality may, however, come with costs, including reductions in predator detection/defence capability, resource defence/monopolization potential, access to mates, and opportunities for social learning (Krause \& Ruxton, 2002).

In addition to regular habitat variability, animals must also increasingly contend with habitat changes brought on by climate change and human disturbance (Overpeck et al., 1990; Corlett \& Lafrankie Jr., 1998; Radchuk et al., 2019). For example, the 2015/16 El Niño event was the strongest during the twenty-first century, and led to devastating fires across Southeast Asia from July to November 2015 (Lim et al., 2017; Miettinen et al., 2017). Between 2.6 and 4.6 million hectares of land were burned in Indonesia alone, and a substantial portion $(37 \%$ to $45 \%$ ) of this occurred in peatland, emitting between 0.89 and 1.75 gigatons of carbon dioxide into the atmosphere (Glauber et al., 2016; Miettinen et al., 2017; Lohberger et al., 2018). Southeast Asia experienced high smoke exposure from July to October 2015, with the most intense haze occurring in September and October (Koplitz et al., 2016; Erb et al., 2018). These fires, and the subsequent haze, had devastating economic, public health, and environmental impacts across Indonesia and Southeast Asia (Glauber et al., 2016; Tacconi, 2016; Harrison et al., 2016; Meijaard, 2018; Kiely et al., 2020). Furthermore, because in the humid tropics plant productivity depends on sunshine (e.g., Wright \& van Schaik, 1994; van Schaik \& Pfannes, 2005), there are clear links between such wide-spread forest fires, the smoke haze that they produce, reductions in plants' photosynthetic capacities, and thus reductions in forests' fruit productivity (Davies \& Unam, 1999; Kobayashi et al., 2005; Calder et al., 2010; Stiegler et al., 2019). This change in resource landscape is likely to have had severe consequences for the animals living in these forests, even in forests that were left unburned and intact. 
Long-term field studies of orangutans (genus Pongo) present an excellent opportunity to investigate how the 2015 fires, and specifically the resulting changes in fruiting patterns, affected the behaviour and sociality of a keystone species. Orangutans are semi-solitary great apes, with flexible, individual-based fission-fusion social dynamics, wherein the only long-term cohesive social units are mothers with their dependent offspring (Galdikas, 1985b; van Schaik, 1999; Knott et al., 2008). After weaning and the birth of a younger sibling (mean IBI $=7.5$ years: van Noordwijk et al., 2018), an immature orangutan may stay in association with its mother (and younger sibling) for several more years. Mothers, however, become gradually less tolerant of their weaned offspring, especially when they feed in proximity (van Noordwijk et al., 2009), and although temporary associations with their mothers are frequent, weaned immature offspring increasingly range alone (Ashbury et al., 2020).

Despite their limited gregariousness, orangutans do not lack social organization nor do they associate randomly. Whereas adult males range over very large distances in search of receptive females and areas with high fruit availability (Spillmann et al., 2017; Galdikas, 1985a; Galdikas, 1985c; Dunkel et al., 2013; Utami Atmoko et al., 2009), female orangutans are philopatric and form 'clusters' of maternally-related females whose home ranges overlap (Singleton \& van Schaik, 2002; Singleton et al., 2009; Arora et al., 2010; Morrogh-Bernard et al., 2011; Arora et al. 2012; van Noordwijk et al. 2012). Because they are not territorial, female orangutans have opportunities to associate with other related (maternally) and unrelated adult females, but they preferentially associate with their relatives (Singleton and van Schaik 2002; Knott et al. 2008; Morrogh-Bernard et al., 2011; van Noordwijk et al. 2012; Ashbury et al. 2020). In addition to being less common, associations between unrelated female orangutans are usually shorter in duration, and often include or end with agonistic interactions (Knott et al. 2008; van Noordwijk et al. 2012).

Because orangutans are primarily frugivorous (MacKinnon 1974; MorroghBernard et al. 2009; Russon et al. 2009), variability in habitat fruit abundance affects orangutans' association patterns. Differences between orangutan populations suggest that there is an evolved effect of long-term fruit abundance on association rates: orangutans living in more fruit-abundant habitats are more gregarious than those living in habitats with lower, or more seasonally variable, fruit abundance (Roth et al. 2020; Mitra Setia et al. 2009; van Schaik et al. 2009). Within sites, however, the effect of temporal fluctuations in fruit abundance on associations varies, with some studies reporting that the mean party size of orangutans increases with increasing fruit availability (Sugardjito et al. 1987), and others that it is not affected by variation in fruit availability (van Schaik 1999; Wich et al. 2006; Harrison et al. 2010; Roth et al. 2020), and that the probability of association is higher when habitat fruit availability is higher (Sugardjito et al. 1987; Roth et al. 2020) — suggesting that orangutans may be more likely to meet and associate briefly at fruit patches when fruit availability is higher. By avoiding association, especially multi-day 'travel' associations during times or in areas with low fruit availability (Kunz et al. 2021), orangutans are able to limit direct feeding competition with conspecifics. 
While orangutans prefer to eat nutrient-rich pulpy fruits when available, they have very broad and flexible omnivorous diets (Leighton 1993; Russon et al. 2009). This allows them to cope with seasonality in their habitats: during periods of fruit scarcity, orangutans switch to an energy-saving mode by minimizing their movement (Wich et al. 2006; Vogel et al. 2015) and focusing their diets on ubiquitous foods with lower energetic value, such as leaves, bark, and pith (Knott 1998; Morrogh-Bernard et al. 2009; Vogel et al. 2009; Bastian et al. 2010; Campbell-Smith et al. 2011). Even in abnormally marginal circumstances, orangutans are resilient: at one study site, orangutans survived for several years on low quality diets after major fires in 1997-1998 directly damaged many of the study population's regular fruit sources (Russon et al. 2015). Furthermore, orangutan population numbers affected by logging activities can rebound with adequate subsequent forest protection (Harrison et al. 2021).

Despite this resilience, individual orangutan health and condition may be severely impacted under particularly adverse conditions. For example, orangutans living in heavily altered plantation landscapes, where long-term access to abundant and varied food resources is limited, had relatively low body mass, suggesting energetic stress (Rayadin and Spehar 2015). With respect to the 2015 peat and forest fires, flanged adult male orangutans had a negative energy balance during and immediately after the hazy period at Tuanan, Central Kalimantan, Indonesia, even when fruit was still abundant (Erb et al. 2018). This may have been because of increased production of stress hormones or an immune response to the fires and smoke (Erb et al. 2018). Importantly, these effects persisted after the fires and after the smoke period for at least the first 2-3 months, suggesting prolonged negative health consequences of the fires on orangutans (Erb et al. 2018). Similar evidence of changes in energetic balance were not found at Sabangau, a nearby, similarly affected, orangutan research site; however, orangutans at this site did show behavioural changes suggestive of energy-saving strategies after the 2015 fires (Gwynn 2020). Overall, there is ample evidence that forest fires can have significant direct and indirect impacts on orangutan diet, health, and activity.

Here, we explore some of the indirect effects of widespread peat and forest fires on Bornean orangutans (Pongo pygmaeus wurmbii). In the Tuanan study area, the thick haze from the 2015 peat and forest fires was followed by a dramatic decline in forest fruit productivity (Fig. 1): after the fires, there was a prolonged (33+ months) period of below-mean fruit productivity (henceforth, the "post-fire period"), which was far longer than the usual dips (1 to 9 months long) in fruit availability that occurred prior to the fires (henceforth, the "pre-fire period"). Our aim was to better understand the effects of the uncharacteristically long period of fruit scarcity that followed the 2015 fires on female orangutan behavior and sociality at Tuanan. We hypothesized that, as a fission-fusion species, orangutans would respond to extreme and long-term fruit scarcity by not only adjusting their activity patterns and diets, but also by associating less with conspecifics. We focussed on associations among parous females, as adult females have full control over the initiation and maintenance of associations with other adult females (as opposed to associations with adult males) and can choose freely when, and when not, to associate with each other (Galdikas 1985b; Kunz et al. 2021). Furthermore, theory predicts that 


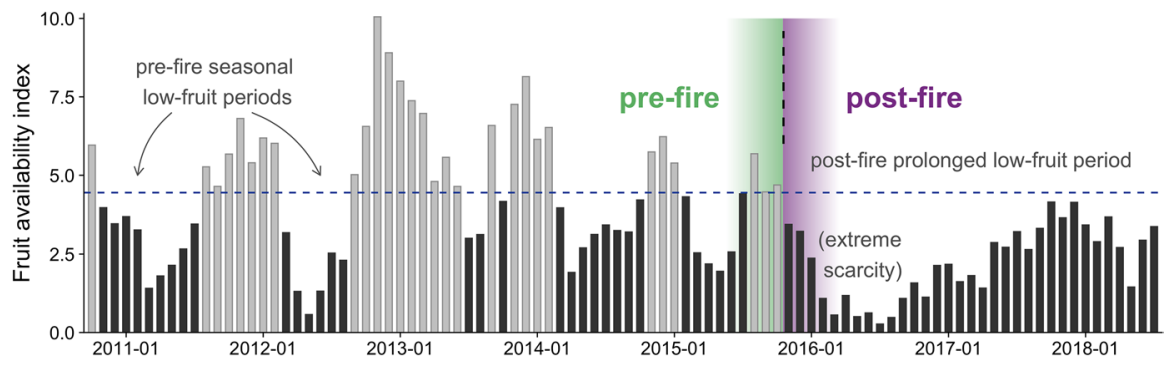

Fig. 1 Timeline of the fruit availability index (FAI) at Tuanan, Indonesia, from October 2010 to July 2018. The horizontal dotted line shows the long-term mean FAI value (4.46), and black bars represent months with data included in this study. The vertical dashed line marks the break between data included in the 'pre-fire' (green) and 'post-fire' (purple) periods.

female behaviour and social relationships will be the most directly affected by variation in fruit availability (Sterck et al. 1997; Young \& Isbell 2002), and the comprehensive longitudinal study of female orangutans is enabled by their philopatry (e.g., van Noorwijk et al. 2012; Ashbury et al. 2020).

We first investigated the direct ecological consequences of this period of extended fruit scarcity on female orangutan behaviour by comparing their activity budgets, daily travel distances, and diets during the pre- and post-fire periods and across variation in fruit availability. We then investigated the social consequences of the period of extended fruit scarcity, by comparing the probability of, time spent in, and rates of agonism within, associations between adult females and their weaned immature offspring, their adult female relatives, and other unrelated adult females, during the pre- and post-fire periods and across variation in fruit availability.

\section{Methods}

\section{Data Collection}

\section{Study site}

We use data collected by the Tuanan field team at the Tuanan Orangutan Research Station $\left(2^{\circ} 09^{\prime} \mathrm{S} ; 114^{\circ} 26^{\prime} \mathrm{E}\right)$, located in the Mawas Reserve, Central Kalimantan, Indonesia, between October 2010 and July 2018. This peat-swamp forest habitat has largely recovered from selective logging that occurred in the 1990s. The study area is $c a$. 1200-ha of homogenous forest with no altitudinal gradient, on the southwestern edge of the $c a$. $3000-\mathrm{km}^{2}$ Mawas Reserve. Fruit patches are relatively small and scattered, as is characteristic of peat-swamp forests, with only a few species of large fruiting trees. The orangutan population density in this area is approximately 4.25-4.5 individuals $/ \mathrm{km}^{2}$, making it the densest wild orangutan population recorded on Borneo (van Schaik et al. 2005; Husson et al. 2009).

The El Niño year of 2015 was the second driest year in the area since long-term research began at the site in 2003 (cumulative annual rainfall at Tuanan in 2015: 
$2145 \mathrm{~mm} ; 2004$ to 2017 range $=1905-4176 \mathrm{~mm}$, mean $\pm \mathrm{SD}=2798 \pm 656 \mathrm{~mm}$; Tuanan Project, unpublished data). Fires directly destroyed extensive areas of forest near and around the study area, including $c a .90$ hectares within the borders of our study area (Fig. S1), and a thick smog blanketed the region for a total of 95 days (in August-November). In the aftermath, beginning in November 2015, the remaining forest experienced a prolonged period ( $>32$ months) of below-mean fruit productivity.

\section{Study periods and fruit availability index (FAI)}

We assessed fruit availability in the study area each month by monitoring phenology plots containing 1,868 tagged stems with $a \geq 10 \mathrm{~cm}$ diameter at breast height (dbh). Measured stems included only trees, as there were no lianas $\geq 10 \mathrm{~cm} \mathrm{dbh}$ in the phenology plots (Tuanan Project, unpublished data). To estimate fruit abundance, we calculated the fruit availability index (FAI) as the percentage of stems (trees) bearing fruit in the phenology plots each month (as per Vogel et al. 2009). This simple estimate of habitat fruit abundance is a meaningful habitat measure for Bornean orangutans (especially adult females); the percentage of stems bearing fruit in the habitat correlates significantly with their diet item selection, energetic and macronutrient intake, estimated lean body mass, many aspects of their behaviour, and activity budgets (Vogel et al. 2012, 2016; O'Connell et al. 2021), as well as population-level movement between habitat types in a mosaic environment (Marshall et al. 2021).

From 2010 to 2015, FAI had periodic, short-term fluctuations. Although high and low FAI periods were not confined to predictable times of the year, we refer to fluctuations in FAI between 2010 and 2015 as "seasonal" because increases and decreases occurred cyclically over time, and high and low FAI periods had short, sub-annual, durations. In 2016, fruit became extremely scarce, and although FAI slowly rebounded towards the long-term mean, even by the end of our study in July 2018, it had not reached mean level nor resumed seasonal high-low cycles (Fig. 1). In our analysis, we included only data collected during months that had a FAI less than or equal to the long-term mean FAI, based on all months between October 2010 to October 2015, inclusive (i.e., mean FAI over the course of the entire "usual fruiting patterns" period $=4.46, \mathrm{SD}=2.06$, range $=0.57-10.05$ ). Previous studies of Bornean orangutans (including some at Tuanan) have used cut-offs of FAI at $c a$. 5 to classify "low" or "limited" fruit availability (Vogel et al. 2009, 2012, 2016), and demonstrated meaningful relationships between these categories of FAI and orangutan diet and behaviour, suggesting that our cut off of 4.46 is not only numerically parsimonious, but is also ecologically meaningful for orangutans; we focussed our investigation on potential variation that occurs within the range of FAI that previous studies have classified as "low." This included all months from after the fires $(n$ months $=33$; FAI mean $=2.24, \mathrm{SD}=1.16$, range $=0.27-4.16)$, but excluded a subset of above-mean FAI months from before the fires $(n$ months included $=32$ out of 61 months), which allowed us to conduct a more robust comparison between the pre-and post-fire periods, keeping FAI within the same range. We used data 
collected between October 2010 and October 2015 for the "pre-fire" period, and between November 2015 and July 2018 for the "post-fire" period (Fig. 1).

\section{Focal sampling}

Our study includes focal data from 13 parous females who live, at least partly, within the Tuanan study area. Of these females, eight had previously been observed to range in the forest area that was burned in 2015, and two lost over $c a$. $40 \%$ of their known pre-fire ranging areas (Fig. S1). After the fires, all females continued to range in roughly the same parts of the study area as before, but discontinued use of the burned area (Meric de Bellefon 2017). It is possible that some females ranging in the northern part of our study area may have expanded their ranges north-east, away from the burned area (but as this is outside of our study area, we do not have data to measure this). We classified focal females based on their genetic relationships and maternal pedigrees as either related (belonging to the same matriline) or unrelated (belonging to different matrilines) (as per Arora et al. 2012).

We collected data during full-day focal follows from morning nest to night nest using standardized field methods (https://www.aim.uzh.ch/de/orangutannetwork/ sfm.html). We collected focal behaviour data at 2-minute instantaneous intervals, noting: (i) the focal animal's activity, (ii) the food type and species if the focal animal was eating, and (iii) the identity and distance to all other orangutans that were within $c a .50$ meters of the focal animal. We considered orangutans "in association" when we estimated them to be within $50 \mathrm{~m}$ of each other, and "in proximity" when estimated to be within $10 \mathrm{~m}$ of each other. We considered orangutans to be "co-foraging" when they ate the same food item from the same tree or liana species within an estimated $10 \mathrm{~m}$ of each other. We also recorded social interactions continuously in detail throughout the focal follows, including aggressive interactions (slapping, grabbing, biting, pushing, chasing, and/or obvious avoidance or submissive behaviour such as fleeing or screaming).

We marked the location of the focal animal at every morning and night nest, as well as on the hour and half-hour throughout the day, on hand-drawn maps (2010-2012), or on hand-held GPS units (2012-2018). We used Garmin MapSource (v6) and ESRI's ArgGIS (v9.3) to digitize hand-drawn maps and to import GPS unit data. We calculated day journey lengths (DJLs) for each focal follow by summing the cumulative Euclidian distance from the morning nest, through each 30-minute point, to the night nest. We calculated daily displacements as the direct Euclidian distance from the morning nest to the night nest.

We divided food items into five categories: 1) tree fruit included any fruits eaten from free-standing woody plants (i.e., that which is included in the measurement of FAI); 2) other fruit included any fruits eaten from lianas (including figs) or ground vegetation (such fruit was not measured by FAI because stem dbh was never $\geq 10$ $\mathrm{cm})$; 3) fallback foods included bark, pith, leaves, flowers, and other coarse or nonleafy vegetative matter (classified as fallback foods by Bastian et al. 2010 and Vogel et al. 2016); 4) insects included all invertebrates (e.g., termites, ants, and caterpillars); and 5) kamunda included any plant parts (fruits, flowers, and leaves) from the liana Leucomphalos callicarpus (subfamily: Papilionoideae). We subtracted 
kamunda parts from the other categories, so they are not counted twice in this analysis. We chose to separate kamunda food items from other foods, as our extensive field observations have suggested that this is a key resource for orangutans at Tuanan; it is widely dispersed in small patches, and is available and eaten almost daily regardless of habitat FAI. We removed one follow block from the diet analysis as it was an extreme outlier: during a rare period of extremely high caterpillar abundance, only one female was followed, and she consumed caterpillars during $\mathrm{ca}$. $70 \%$ of her feeding time.

\section{Ethical Note}

This was a strictly observational study of habituated wild animals. Observers kept a distance of at least $10 \mathrm{~m}$ from all orangutans. The research protocol adhered to the legal requirements of Indonesia and was approved by the Ministry of Education, Culture, Research and Technology of the Republic of Indonesia (Kemendikbud Ristek) and the Directorate General of Natural Resources and Ecosystem Conservation - Ministry of Environment and Forestry of Indonesia (KSDAE-KLHK), the Ministry of Internal Affairs, Indonesia, the Nature Conservation Agency of Central Kalimantan (BKSDA); the protocol also adhered to the guidelines set forth by the Animal Behaviour Society. The authors declare that they have no conflicts of interest.

Data Availability We have included all data analysed during this study in the supplementary information files of this published article (Table S2).

\section{Statistical Analysis}

Each data point in the analysis is one follow block consisting of four to 12 full-day follows of a particular focal female within a 30-day period ( $n$ follow blocks $=128$; mean \pm SD follow days in a block $=6.1 \pm 1.76$ ). For follow blocks that crossed calendar months (the boundaries by which we estimated certain variables, e.g., offspring ages, or measured, e.g., habitat FAI), we used the weighted mean of any applicable monthly values.

For certain analyses, we used only subsets of the data (see details in Table S1). Most notably, for the analysis of related adult female sociality, we included only females belonging to a single matriline ( $n$ females $=6, n$ follow blocks $=84$ ). These six females are all closely related (a female and her three adult daughters and two adult grand-daughters) and have highly overlapping home ranges (see van Noordwijk et al. 2012; Ashbury et al. 2020); thus, there is ample opportunity for these females to associate with related females. Other focal females had far fewer known maternal relatives living within the study area, and thus their data would have contributed mostly zeros to the analysis of related adult female sociality.

Table S1 gives an overview of the type of model that we fit for each outcome variable, the fixed and random effects that we included in each model, and the subset (if applicable) of the data to which we applied each model. For each outcome variable of interest, we included at least the following three fixed effects in the model: 1) FAI 
(FAI during the follow block), 2) period (pre-fire or post-fire), and 3) an interaction between FAI and period. Additionally, in all models, we included specific terms that needed to be controlled for as fixed effects (e.g., offspring age) and random effects (e.g., focal ID). We considered a fixed effect to be a significant predictor of the outcome variable if its associated $p$-value was below the alpha value that we calculated for each group of models that had closely related outcome variables. We calculated alpha values by dividing 0.05 by the number of models in the group (i.e., a Bonferroni multiple-comparison correction; listed in Table $\mathrm{S} 1$ ). We measured effect sizes by calculating the standardized coefficients of each model and their $95 \%$ CIs, and we have reported their categorical size (in accordance with Cohen 1988). We checked for collinearity between fixed effects, and assured that all variance inflation factor values for main effects were $<5$, indicating low correlation between predictor variables (James et al. 2013).

For questions concerning the time spent engaging in a behaviour (e.g., amount of time spent feeding), we fit negative binomial GLMMs (with log link functions), in which the outcome variable was the cumulative count of time, in minutes, over the follow block that the focal spent engaging in that behaviour, offset by the (log) number of days in the follow block, and weighted by the number of days in the follow block. We chose to use cumulative time measures, rather than proportional time measures (e.g., number of minutes spent in proximity rather than proportion of association time spent in proximity) because we were most interested in how the time spent engaging in each behaviour varied in and of itself, and not as a function of another variable. Because all follow blocks consisted only of full-day follows, and we included the number of days in the follow block as an offset in each model, essentially, we are estimating the mean duration of each behaviour per 24-hour day. The models for the diet analysis of tree fruit, other fruit, and insects were zeroinflated, but there were no clear patterns in zero occurrence, and so we included a single zero-inflation parameter that applied to all observations.

For questions concerning the time spent in association with conspecifics, we fit hurdle models in which the outcome variable was the cumulative count of time in minutes over the follow block that the focal spent engaging in that behaviour, weighted by the number of days in each follow block. These models are essentially a two-step process: first, the probability of a zero-value is modelled with a binomial GLMM (with logit link function), weighted by the number of days in the follow block; and second, all non-zero values are modelled using a truncated negative binomial GLMM (with log link function), offset by the (log) number of days in the follow block, and weighted by the number of days in the follow block. Essentially, these models generate two results: 1 ) the predicted probability that the behaviour did not occur at all during the follow block, and 2) where the behaviour did occur, the predicted mean duration during which it occurred per 24-hour day. We chose to fit hurdle models rather than zero-inflation models because 1) these social behaviours are conspicuous and obvious enough to field observers that we are confident in ruling out false zeros, and 2) previous studies have given conflicting results concerning the effects of variation in fruit availability on orangutans' probability of association and their mean party sizes, suggesting that an orangutan's decision to initiate, versus its decision to maintain, social interactions may be guided by different underlying 
mechanisms (see Introduction). As such, hurdle models, which allow for differences in the predictive power of fixed effects on the occurrence $(0 / 1)$ and duration of a behaviour, are more parsimonious than zero-inflation models for these rare behaviours.

For questions concerning the proportion of days on which an agonistic interaction occurred, we fit binomial GLMMs (with logit link functions) and quasibinomial GLMs (with logit link functions), with the outcome variable as the proportion of days in the follow block during which an agonistic interaction took place, and weighted by the total number of days in the follow block. We fit GLMs where sample sizes were too small for mixed modelling. We checked that the overdispersion parameters for binomial GLMMs were $<1.5$.

For the analyses of daily journey length (DJL) and daily displacement, we fit Gaussian LMMs on follow block mean values, weighted by the number of days in each follow block, and fit by maximum likelihood. We visually checked residuals to ensure a normal distribution.

All model result plots show the raw data (points) and predicted values (lines) of the behaviour of interest during the pre- (green, circles) and post- (purple, triangles) fire periods, plotted against FAI. The predicted values that we show in the plots are the marginal effects of FAI and period when holding other terms constant at their means. The shaded ribbons indicate the approximate $95 \%$ confidence intervals (CIs), calculated as $+/-1.96 \times \mathrm{SE}$, and both the prediction lines and CIs extend along the $x$-axis to the minimum and maximum FAI values in the dataset during each period. The binomial model portions of the hurdle models predict the probability of the behaviour not occurring (i.e., the probability of a zero value) and this is what is reflected in the model estimates (in text and in Table S1). However, in order to make our plots easier to read and more intuitive, we have reversed the model predictions, and so plots depict the probability of that behaviour occurring.

We performed all analyses in R (R Core Team 2020), using RStudio (RStudio Team 2020). We fit linear mixed models (LMMs) using the lme4 (Bates et al. 2015) and lmerTest (Kuznetsova et al. 2017) packages. We fit all generalized linear mixed models (binomial, negative binomial, and hurdle GLMMs) using the glmmTMB package (Brooks et al. 2017) with the nbinom 2 distribution family [see Table S1 for raw model outputs, including unstandardised coefficients (B)]. We calculated standardized model coefficients $(\beta)$, their $95 \%$ CIs, and categorical effect sizes (reported in text) using the report package (Makowski et al. 2020). We checked collinearity of predictor variables using the performance package (Lüdecke et al. 2020). We used the ggeffects package (Lüdecke 2018) to calculate the marginal effects and 95\% CIs of model terms of interest, and then plotted these using the ggplot2 (Wickham 2016) and cowplot (Wilke 2020) packages.

\section{Results}

Table S1 gives an overview of the sample sizes, summary statistics, and model estimates for each statistical model, and we report standardized coefficient and effect sizes of statistically significant interaction effects in the text. 

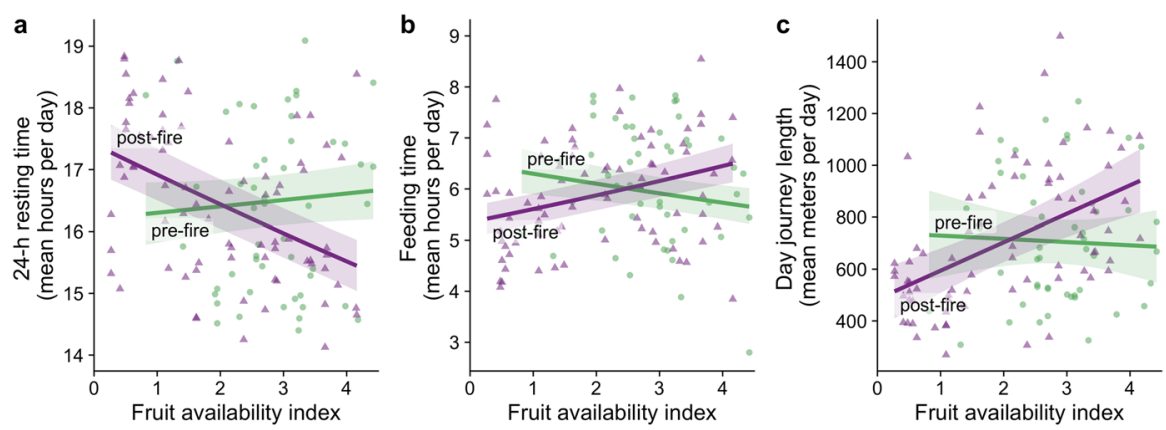

Fig. 2 Activity of female orangutans at Tuanan, Indonesia, from October 2010 to July 2018. Predicted values of the mean per day (a) time spent resting (including day-time resting and overnight sleeping), (b) time spent feeding, and (c) day journey length (DJL), during the pre-fire (green) and post-fire (purple) periods, plotted against the fruit availability index (FAI). Shaded areas show the $95 \%$ confidence intervals. Points represent the raw data values of follow blocks during the pre-fire (green circles) and post-fire (purple triangles) periods.

\section{Basic behavioural ecology}

The mean time that adult female orangutans spent resting (including overnight and daytime resting) and feeding per day were both predicted significantly by interaction effects between FAI and period, although effect sizes were very small (resting: $\beta=-0.04,95 \%$ CI [ $-0.05,-0.03]$, Fig. 2a; feeding: $\beta=0.09,95 \%$ CI [0.06, 0.12], Fig. $2 \mathrm{~b}$ ). During the pre-fire period, female orangutans spent more time resting and less time feeding as FAI increased towards the long-term mean level. During the post-fire period, however, they spent less time resting and more time feeding as FAI increased.

Female's DJL was also significantly predicted by an interaction between FAI and period, with a medium effect size ( $\beta=0.55,95 \%$ CI [0.17, 0.93]; Fig. 2c). During the pre-fire period, female orangutans' DJLs decreased very gradually with increasing FAI. During the post-fire period, however, there was a strong positive correlation, with DJL increasing sharply as FAI increased towards the long-term mean. We found similar results, indicating a significant interaction, with a medium effect size, between period and FAI, for daily displacement ( $\beta=0.53,95 \% \mathrm{CI}[0.15,0.90])$.

The total time that female orangutans spent feeding on tree fruit, other fruit, fallback foods, and kamunda were all significantly predicted by an interaction effect between FAI and period, with medium (tree fruit, fallback foods), and small (other fruit, kamunda) effect sizes (tree fruit: $\beta=0.55,95 \%$ CI [0.38, 0.73], Fig. 3a; fallback foods: $\beta=-0.65,95 \%$ CI [ $-0.86,-0.43]$, Fig. 3 c; other fruit: $\beta=0.30,95 \% \mathrm{CI}$ [0.10, 0.49], Fig. 3b; kamunda: $\beta=-0.28,95 \%$ CI [ $-0.39,-0.17]$, Fig. 3e). In both periods, we found a positive correlation between FAI and feeding time for tree fruit and other fruit, and a negative correlation for fallback foods; however, the slopes of the relationships were much steeper during the post-fire phase. The only period during which adult female orangutans did not spend any time eating fruit during an entire follow block was during extreme and persistent fruit scarcity (i.e., post-fire 

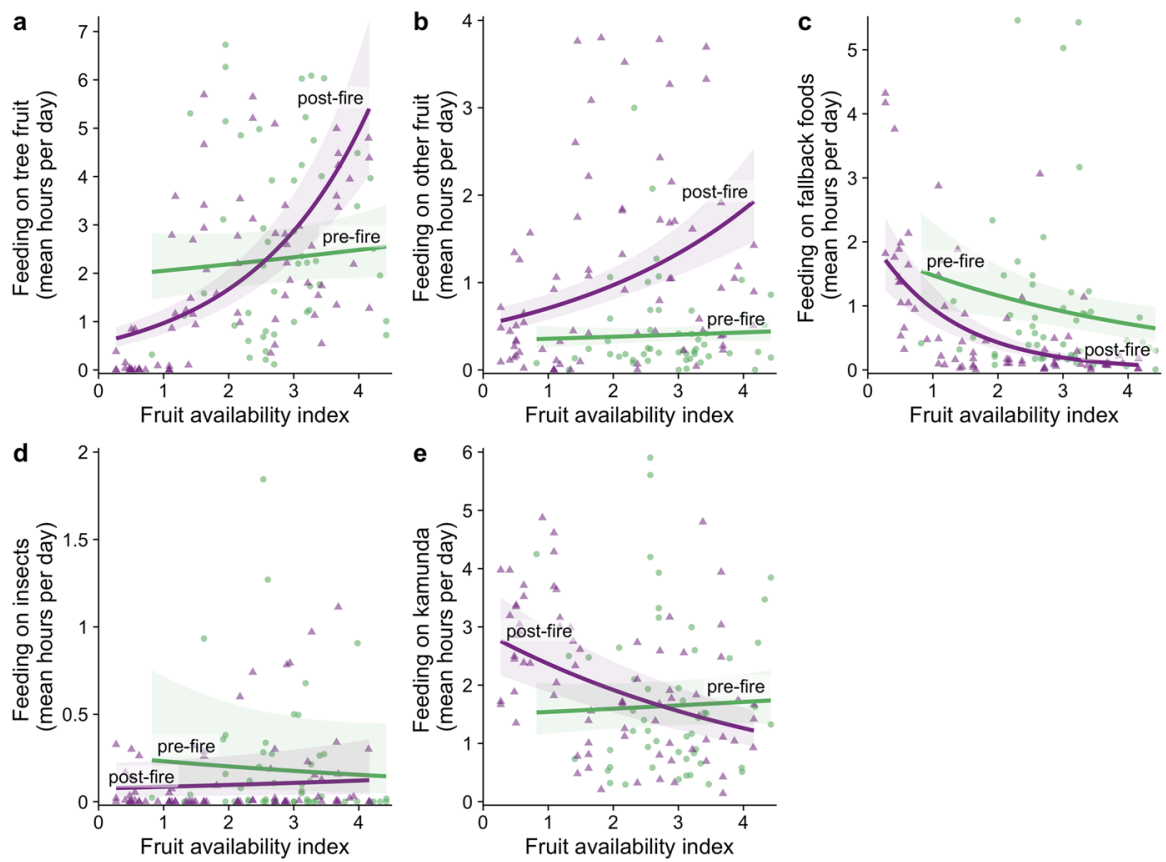

Fig. 3 Diet of female orangutans at Tuanan, Indonesia, from October 2010 to July 2018. Predicted values of the mean time per day spent feeding on (a) tree fruit, (b) other fruit, (c) fallback foods, (d) insects, and (e) kamunda, during the pre-fire (green) and post-fire (purple) periods, plotted against the fruit availability index (FAI). Shaded areas show the $95 \%$ confidence intervals. Points represent the raw data values of follow blocks during the pre-fire (green circles) and post-fire (purple triangles) periods.

low FAI) when FAI was $<1.5$. The amount of time that females spent feeding on kamunda was weakly correlated with FAI during the pre-fire period, but showed a stronger negative correlation with FAI during the post-fire period. Kamunda is the only food type category that was consumed during every single follow block, indeed of the 781 nest-to-nest focal follows included in our data set, only nine had no record of kamunda feeding. Female orangutans consumed insects significantly more during the pre-fire period than during the post-fire period (medium effect size, $\beta=-0.66$, $95 \%$ CI [ $-0.97,-0.35]$, Fig. 3d); however, the magnitude of the largest predicted difference is only a matter of a few minutes, so this may not be ecologically relevant.

\section{Socio-ecology}

\section{Mothers and their weaned immature offspring}

All aspects of sociality between mothers and their weaned immature offspring were significantly predicted by the age of the offspring: as weaned offspring matured, the probability of, and time spent in, association, proximity, and co-foraging with their mothers decreased. When controlling for offspring age, the probability of 

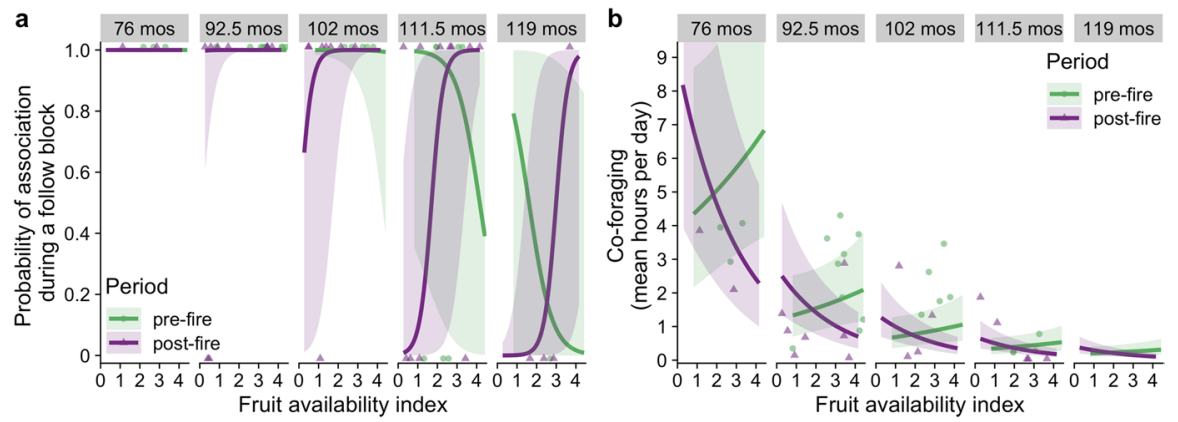

Fig. 4 Socio-ecology of mother orangutans and their weaned immature offspring at different ages at Tuanan, Indonesia, from October 2010 to July 2018. Predicted values, split by weaned immature age (in months, top grey bars), of (a) the probability that mothers spend time in association during a follow block, and (b) the mean time per day that mothers spend co-foraging (given that it did occur), with their weaned immature offspring, during the pre-fire (green) and post-fire (purple) periods, plotted against the fruit availability index (FAI). Predictions are shown for the minimum, first, second, and third quartiles, and the maximum weaned immature ages in the dataset. Shaded areas show the $95 \%$ confidence intervals. Points represent the raw data values - discretized to 0/1 in plot a - of follow blocks during the pre-fire (green circles) and post-fire (purple triangles) periods, and are situated in the age panel that is closest to the immature's actual age during the follow block.

mothers and weaned immatures spending any time in association and in proximity was significantly predicted by an interaction between FAI and period, with a large effect size for each (probability of association: $\beta=-5.95,95 \%$ CI $[-9.02,-2.87]$, Fig. 4a; probability of proximity: $\beta=-3.84,95 \%$ CI $[-6.34,-1.34]$, Fig. S2a): both decreased as FAI increased during the pre-fire period, and increased as FAI increased during the post-fire period, although this effect is seen mostly among older immatures. Where associations did occur, the time spent in association and in proximity was not significantly predicted by FAI nor period.

When controlling for offspring age, the probability of mothers and their weaned immatures co-foraging was predicted by the amount of time that mothers spent feeding: when mothers spent more time feeding, there was a higher probability of coforaging. When co-foraging did occur, the time spent engaging in this behaviour was significantly predicted by an interaction between FAI and period, with a medium effect size ( $\beta=-0.54,95 \%$ CI $[-0.78,-0.29])$ : the time spent co-foraging increased as FAI increased during the pre-fire period, but decreased as FAI increased during the post-fire period (Fig. 4b). Furthermore, the rate of agonism between mothers and their weaned immatures was highest during post-fire low FAI, however, this trend was not significant (Fig. S2b).

\section{Related adult female sociality}

The probability of a female spending any time in association or in proximity with another related adult female were both significantly predicted by medium-sized interaction effects between FAI and period (association: $\beta=-0.64,95 \%$ CI $[-1.10$, $-0.19]$, Fig 5a; proximity: $\beta=-0.58,95 \%$ CI $[-1.04,-0.11]$, Fig S3b), with the 

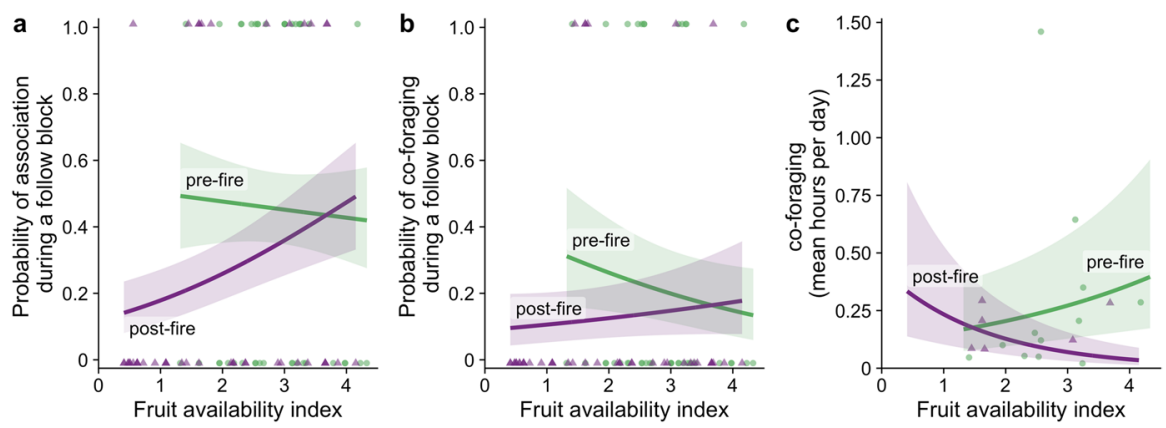

Fig. 5 Socio-ecology of related adult female orangutans at Tuanan, Indonesia, from October 2010 to July 2018. Predicted values of the probability that adult females spend time (a) in association, and (b) co-foraging, during a follow block, and - given that the behaviour did occur at all - the (c) predicted time that adult females spend co-foraging, with related adult females, during the pre-fire (green) and post-fire (purple) periods, plotted against the fruit availability index (FAI). Shaded areas show the $95 \%$ confidence intervals. Points represent the raw data values - discretized to $0 / 1$ in plots $\mathbf{a}$ and $\mathbf{b}-$ of follow blocks during the pre-fire (green circles) and post-fire (purple triangles) periods.

lowest probabilities occurring during post-fire low FAI (Fig. 5a, S3a). Where association did occur, the duration was not significantly predicted by FAI nor period (Fig S3a). We found similar patterns for time spent in proximity, with females generally spending approximately $75 \%$ of their time in association in proximity, although neither FAI nor period were significant predictors (Fig. S3c). The probability of coforaging between related females was significantly lower during the post-fire period than during the pre-fire period (medium effect size, $\beta=0.69$, 95\% CI [0.12, 1.25], Fig $5 b$ ). Where co-foraging did occur, the duration of co-foraging was significantly predicted by a large interaction effect between FAI and period ( $\beta=-1.00,95 \% \mathrm{CI}$ $[-1.36,-0.64])$ : there was a positive correlation between time spent co-foraging and FAI during the pre-fire period, and a negative correlation during the post-fire period (Fig. 5c). The probability of agonism occurring between two related adult females was not predicted by FAI nor period (Fig. S3d).

\section{Unrelated adult female sociality}

The probability of a female spending any time in association and in proximity with an unrelated adult female were both significantly predicted by large interaction effects between period and FAI (association: $\beta=-1.27,95 \%$ CI $[-1.81,-0.73]$, Fig. 6a; proximity: $\beta=-1.30,95 \%$ CI $[-1.88,-0.73]$, Fig. $6 \mathrm{~b})$. In both cases, the probability was lowest during the post-fire low FAI period. Where association and proximity did occur, the duration was not significantly predicted by FAI nor period (Fig S4a, and S4b). The probability of agonism occurring between unrelated adult females was also predicted by an interaction between period and FAI $(\beta=-2.44$, $95 \%$ CI $[-4.13,-1.02])$, with a negative correlation between the probability of agonism and FAI during the post-fire period and a positive correlation during the prefire period (Fig. 6c). 

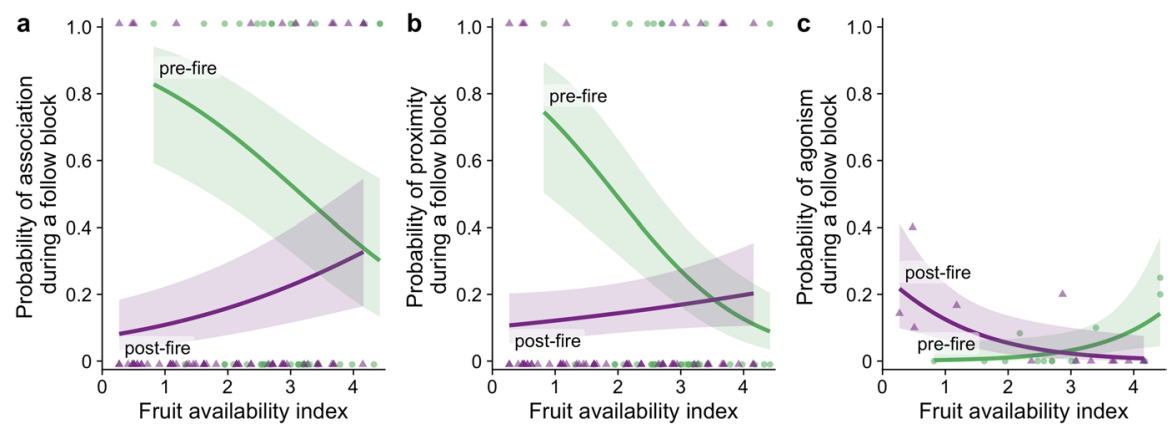

Fig. 6 Socio-ecology of unrelated adult female orangutans at Tuanan, Indonesia, from October 2010 to July 2018. Predicted values of the probability that unrelated adult females (a) spend time in association, (b) spend time in proximity, and (c) exhibit agonism towards each other during a follow block, during the pre-fire (green) and post-fire (purple) periods, plotted against the fruit availability index (FAI). Shaded areas show the $95 \%$ confidence intervals. Points represent the raw data values - discretized to $0 / 1$ in plots $\mathbf{a}$ and $\mathbf{b}$ - of follow blocks during the pre-fire (green circles) and post-fire (purple triangles) periods.

\section{Discussion}

We have shown that the relationships between fruit availability and female Bornean orangutan behaviour and sociality during normal, seasonal fluctuations in fruit availability were quantitatively and qualitatively different from those during an extended period of low fruit availability that followed the intense smoke-cover period caused by widespread Southeast Asian peat and forest fires in 2015. Extreme and persistent fruit scarcity (i.e., post-fire low FAI) correlated with female orangutans spending more time resting, spending less time feeding, travelling shorter distances, and diet-switching more intensely from their preferred resources (fruit) to fallback (bark, pith, mature leaves, and coarse vegetative matter) and kamunda food items, than regular seasonal fruit scarcity (i.e., pre-fire low FAI). After the extreme scarcity period, when FAI increased towards the long-term mean, the activity and diet patterns of female orangutans rebounded in the opposite direction, with less time spent resting, more time spent feeding, greater distances travelled, much more time spent feeding on fruit, and less time spent feeding on kamunda and fallback foods, compared to during the pre-fire period.

These basic changes in females' behavioural ecology underly significant changes in their social patterns as well. Extreme and sustained fruit scarcity (i.e., post-fire low FAI) correlated with a reduced probability of socializing between mothers and their weaned immatures, as well as between related adult females, compared with seasonal intermittent low fruit. However, where socializing did still occur, its duration and the levels of social tolerance exhibited therein were not significantly reduced. This stands in contrast to unrelated adult females, between whom extreme fruit scarcity led to a reduced probability of sociality, and also reduced social tolerance - indicated by the higher probability of agonism - during association. After prolonged scarcity, when FAI returned towards the long-term mean, sociality among mothers and their weaned immatures recovered, and even increased beyond 
normal (pre-fire) conditions, while social patterns between related and unrelated adult females generally returned to those exhibited under normal, seasonal fruiting conditions.

Orangutans living in Tuanan's peat-swamp habitat have previously been described as employing a "search-and-find" strategy, wherein they exploit the habitat's available fruit as much as possible, continuously feeding and travelling: with increasing FAI, daily travel distance and active period both increase, while time spent feeding decreases gently (probably because a higher proportion of fruit in the diet requires less processing time than a higher proportion of fallback foods) (Morrogh-Bernard et al. 2009; Vogel et al. 2016). We found general support for this during the pre-fire period: with higher FAI, orangutans spent less time feeding, and showed weak evidence of diet-switching from fallback foods to preferred fruit. However, because we limited our dataset to only adult females and only below-mean FAI months during the pre-fire period, we did not see a strong effect of FAI on diet, nor on active period or daily travel distance during the pre-fire period, and what little effect there was for these latter two variables was in the opposite direction to that predicted based on previous studies (e.g., Vogel et al. 2016).

Paradoxically, we found that during the extended period of below-mean fruit availability (post-fire), female orangutans employed a strategy more closely resembling the "sit and wait" strategy (Morrogh-Bernard et al. 2009) used by orangutans living in masting Dipterocarp forests: they rested more, fed for less time, and travelled shorter distances during times of extreme scarcity, and exhibited a significant decrease in resting time, and an increase in feeding time and daily travel distance, when fruit availability increased towards the long-term mean. This suggests that they were conserving energy when fruit was particularly scarce, and then rebounding and maximizing their potential energetic intake as FAI increased. This is further supported by the strong effect of FAI on diet during the post-fire period: with females eating a relatively large amount of kamunda food items and fallback foods and very little tree and other fruit when fruit was exceptionally scarce, and then showing a very strong increase in the time spent consuming tree and other fruits (while eating hardly any fallback foods) when fruit availability returned towards the long-term mean for this habitat. The consistent and relatively high amount of time spent feeding on kamunda food items across periods and FAI values — indeed, kamunda was the only dietary category that never had predicted values below 1 hour of feeding time per day - suggests that this liana is a key resource for orangutans living at Tuanan.

When fruit is scarce, Bornean orangutans living in masting habitats (i.e., habitats with extended periods of fruit scarcity punctuated every few years by brief periods of high fruit abundance) metabolize fat reserves (Knott 1998) and endure long periods with deficient protein intake (Vogel et al. 2012). A recent study at Tuanan, which includes the post-fire period of fruit scarcity, showed that orangutans (including adult females) had lower estimated lean body mass when FAI was lower (O'Connell et al. 2021). It is therefore likely that the behavioural changes that we observed between the pre- and post-fire periods - from their usual "search-andfind" strategy to one akin to the "sit and wait" strategy that is characteristic of orangutans living in masting habitats (Morrogh-Bernard et al. 2009; Ashbury 2020) 
- are coupled with significant physiological changes, including the catabolism of muscle tissue (O'Connell et al. 2021). These behavioural and physiological changes underlie the significant changes in their socio-ecology which occurred during this period of uncharacteristically long fruit scarcity.

We observed that mothers and their weaned immatures were less likely to spend time in association and in proximity with each other during the post-fire period when fruit was scarce. When associations did still occur, the duration of time spent in association was not reduced, but the rate of agonism from mothers towards their weaned offspring trended towards being higher, especially when FAI was particularly low. Where association did occur and mothers and their weaned immatures coforaged, the time spent co-foraging was actually highest during the extreme scarcity period. This suggests that the reduced probability of association between mothers and their weaned immature offspring during prolonged scarcity may be driven by passive avoidance resulting from the distribution of food sources, with only minimal active social intolerance.

This reduction in time spent in association with their mothers could have lasting effects on weaned immature orangutans. Among chimpanzees, weaned immatures who experience maternal loss suffer various adverse effects, including hampered physical development, later age at first reproduction, lower overall reproductive success, higher risk of mortality, and/or lower overall survival (Samuni et al. 2020; Crockford et al. 2020; Stanton et al. 2020). Similar effects of maternal loss post weaning, but prior to the onset of sexual maturity, have been observed in red deer (Cervus elaphus: Andres et al. 2013), baboons (Papio cynocephalus: Tung et al. 2016), and hyenas (Crocuta crocuta: Watts et al. 2009). These studies suggest that maternal presence, and thus, maternal association - even in the absence of direct maternal investment - clearly serves some vital function(s) for weaned offspring. These long-term effects may be driven by deficits experienced by weaned immatures who do not have (access to) their mothers, i.e., that have fewer opportunities for learning and information transfer, reduced social and physical support against conspecifics and predators, and the absence of any post-weaning food-sharing or tolerated scrounging from their mothers (van Noordwijk 2012). It is therefore possible that the reduction in association with mothers experienced by weaned immatures at Tuanan during the prolonged period of fruit scarcity will have lasting effects on their development, reproduction, and survival.

Among related adult females (and, thus, their dependent offspring), there was a reduced probability of socializing during the post-fire period of extreme fruit scarcity, but as FAI increased toward the long-term mean, the probability of socializing increased towards pre-fire levels. When associations did nevertheless occur during post-fire low FAI, they were not shorter in duration, nor did they have lower levels of social tolerance. Indeed, the time spent in association, in proximity, and co-foraging was not significantly reduced during the post-fire period, even when fruit was extremely scarce, and the probability of agonism was not higher. This suggests that the reduced probability of sociality between related females during this same time may be driven by general avoidance mechanisms, including the reduction in daily travel, likely resulting from the distribution of food resources, rather than active social intolerance. Notably, the probability of association and proximity among 
related adult females during the pre-fire period was essentially constant across FAI values, indicating that - under normal seasonal conditions, and at least within the range of below-mean fruit availability - related adult females' association patterns are unaffected by fruit availability (see also Fröhlich et al. 2020). Together this suggests that the benefits of such rare associations, including play and learning opportunities for the dependents, outweigh the cost of food competition even under scarce conditions (cf. van Noordwijk et al. 2012; Schuppli et al. 2016, 2020).

This stands in contrast to the clearly reduced social tolerance exhibited by unrelated adult females during the post-fire period, beyond that which could be explained by the immediate effects of low fruit availability alone. Under normal, seasonal conditions (i.e., pre-fire), unrelated females were less likely to be in association and proximity, and more likely to aggress each other, as FAI increased. However, when fruit availability was below-mean for the prolonged period (i.e., post-fire), the probability of unrelated adult females being in association or proximity with each other was exceptionally low, regardless of FAI. Furthermore, when they did associate, the rates of agonism between unrelated females were significantly higher. These results thus align with, and expand on, previous studies: not only is there a difference in relationships between related and unrelated females (e.g., Knott et al. 2008; van Noordwijk et al. 2012), but the period of uncharacteristically long fruit scarcity exacerbated the social intolerance among unrelated females, both by reducing the probability of any association at all, and by increasing the probability of agonism during associations. This suggests that the potential benefits gained from such associations between unrelated females are negligible, and do not outweigh the costs of association, especially during times of prolonged low fruit availability.

The large matriline featured in our analysis of related adult female sociality is probably not typical of other orangutan matrilines in Tuanan, nor is it probably typical of matrilines at other sites. Regardless of how generalizable the case of this matriline may be, these females offer an opportunity to compare associations among female relatives with those among nonrelatives. It is possible that, in the absence of an abundance of female relatives and thus there being fewer opportunities to associate with related females, the differences that we see between related and unrelated female social patterns would be less pronounced, disappear, or even be reversed. We expect, however, that similar patterns would be observed, as previous studies from other sites have shown, under site-specific normal fruiting conditions, higher rates of association, and higher social tolerance between known or suspected related adult females than between known or suspected nonrelatives (Singleton and van Schaik 2002; Knott et al. 2008), as has also been observed at Tuanan (this study, and van Noordwijk et al. 2012). This suggests that the qualitative patterns, if not the quantitative measures, that we've described in response to extreme scarcity may be generalizable even to smaller matrilines.

The overall reduction in adult female gregariousness - both with each other and with their weaned immature offspring — may also have lasting effects on their dependent offspring. Dependent offspring use their mothers' associations with other mothers as opportunities to play with peers - a developmentally important activity, for which opportunities are otherwise rare because of orangutans' single births and predominantly solitary lifestyles (van Noordwijk et al. 2009; Fröhlich et al. 2020). 
Reduced gregariousness and social tolerance among mothers, as well as reduced association between mothers and their weaned immature offspring, may therefore have consequences on the development of their dependent offspring: offspring may have reduced opportunities to learn the social, locomotor, and cognitive skills that are fostered through social play and other social learning opportunities (e.g., Byers and Walker 1995; Fairbanks 2000; Graham \& Burghardt 2010; van Leeuwen et al., 2013; Heintz et al. 2017). Furthermore, mothers' sociability in general has the potential to greatly affect immatures' development: infants of more sociable mothers have higher exploratory tendencies - a proxy for problem-solving skills and cognitive abilities - than those of less sociable mothers (Schuppli et al. 2020). Among chimpanzees, mothers of sons are more gregarious than mothers of daughters, and mothers' gregariousness during just the first 6 months of infancy has been shown to predict the social patterns of adult male chimpanzees (Murray et al. 2014; Wellens, 2018). Furthermore, orangutans acquire skills via close-proximity social learning, which is only possible when there are 1) social partners in association, and 2) a high level of social tolerance between associates (van Schaik \& Pradhan 2003; Schuppli et al. 2016). This suggests that mothers' reduced sociability, even just during this single prolonged period of fruit scarcity, could have lasting effects on the social and cognitive development, and learned skill repertoires, of their offspring.

Here, we have ascribed differences between the pre- and post-fire period, given similar fruit availability levels, to the duration of the scarcity periods (multiple short periods during the pre-fire period and one single extended period during the postfire period). However, this does not preclude that the type and spatial distribution of food sources, rather than the duration of scarcity or lack of fruit per se, played a causal role in the observed behaviour and social changes. Furthermore, due to sample size constraints, we were not able to investigate orangutans' behaviour and sociality over the course of the post-fire period; however, there could be meaningful temporal patterns during this time. Further detailed analyses of the forest phenology, as well as orangutan nutrient intake and ranging during this period, could shed more light on the exact mechanisms that underly the behavioural and social changes that we have shown here.

Across orangutans' geographic range, there is a strong link between levels of orangutan gregariousness, density of orangutan populations, and overall habitat fruit abundance: where fruit availability is generally higher, orangutan populations are denser, and orangutans are more gregarious (Mitra Setia et al. 2009; van Schaik et al. 2009). The Tuanan area has the highest orangutan population density recorded on Borneo (4.25-4.5 individuals / $\mathrm{km}^{2}$; van Schaik et al. 2005), and, under normal conditions, is a relatively gregarious population (Husson et al. 2009). However, just as we observed female orangutans at Tuanan altering their activity patterns, we also observed a significant reduction in gregariousness during the period of prolonged scarcity: their behavioural and social patterns resembled those of orangutan populations living in marginal and masting habitats that regularly experience long-term scarcity (van Schaik et al. 2009; Roth et al. 2020; Ashbury \& S. Spehar, unpublished data). This reduced gregariousness and social tolerance, without the reduced population density that usually accompanies it, may increase the riskiness of the social landscape at Tuanan, which - because aggression between females can be 
so serious as to turn lethal (Marzec et al. 2016) — could have major fitness consequences for adult females and their offspring.

As climate change leads to increasingly unpredictable and extreme weather conditions, and the probability and scale of devastating events such as widespread peat and forest fires are exacerbated, understanding the effects of such events on wild animal populations is increasingly important. Here, we showed that an uncharacteristically long period of fruit scarcity - following widespread fires that were exacerbated by a particularly intense ENSO cycle, a symptom of climate change (Field et al. 2016) — affected female Bornean orangutan behaviour and sociality more severely than normal, seasonal habitat variation. Female orangutans at Tuanan completely switched their energetic strategy, weakened their relationships with their weaned immature offspring, and generally became less gregarious and less socially tolerant, especially of unrelated adult females. These indirect effects of the forest fires on orangutans' socio-ecology, combined with other negative health effects (Erb et al. 2018), could have long-lasting indirect fitness consequences for this population, as well as other orangutan populations that experienced similar effects of the 2015 fires (e.g., Gwynn 2020). These fitness consequences may be less severe for orangutans living in mosaic habitats where movement between forest types could allow for some degree of buffering or compensation if faced with sudden prolonged scarcity in a particular habitat type (see: Marshall et al. 2021, Te Boekhorst et al. 1990). However, fitness consequences may be even more extreme for orangutans living in smaller habitat fragments, and/or where a more substantial portion of orangutans' home ranges are burned. The combined effect of local over-crowding - as orangutans who formerly ranged in a burned area rely more on the remaining forest habitat - with a reduction in long-term fruit availability and the associated reduction in social tolerance could lead to higher rates of aggression and/or stress (see: Amrein et al. 2014; Marzec et al. 2016), in addition to the potential for increased parasitic load (see: Wolfe et al. 2002; Gwynn 2020). Thus, the potential fitness consequences that we have observed here would likely be exacerbated in other, less optimal, habitats. As the prevalence and intensity of peat and forest fires in Indonesia continues to increase, the long-term viability of smaller populations, and even the long-term fitness of orangutans in larger populations, is at risk.

Supplementary Information The online version contains supplementary material available at https://doi. org/10.1007/s10764-021-00263-x.

Acknowledgements We thank all the institutions and organizations enabling the Tuanan Orangutan Research Project, including the Indonesian Institute of Science (LIPI), the Ministry of Education, Culture, Research and Technology of the Republic of Indonesia (Kemendikbud Ristek), the Director General of Natural Resources and Ecosystems Conservation-Ministry of Environment and Forestry of Indonesia (KSDAE-KLHK), the Ministry of Internal Affairs, the Nature Conservation Agency of Central Kalimantan (BKSDA), the local government in Central Kalimantan, Kapuas-Kahayan Forest Management Unit (KPHL), the Bornean Orangutan Survival Foundation (BOSF) and their Mawas project in Palangkaraya, and Universitas Nasional (UNAS). We thank the Swiss National Science Foundation (310030B_160363/1), the A.H. Schultz Foundation, the University of Zürich, and Rutgers University for their financial support. Sincere thanks to Dr. Tatang Mitra-Setia for logistical support in Indonesia and to Dr. Erin Vogel for her organizational help, especially with the phenology data. We are grateful to Pak Rahmatd, Abuk, Idun, Isman, Suwi and Tono, and all the students and researchers (from UNAS, the University of Zurich, and Rutgers University, and others) at Tuanan for their contributions to long-term data 
collection. We are also grateful to Dr. Tracy Montgomery for reviewing our data wrangling and analysis $\mathrm{R}$ code, and to Dr. Joanna Setchell (editor) and the two anonymous reviewers for their helpful comments and feedback on our manuscript.

Funding Open Access funding enabled and organized by Projekt DEAL.

Open Access This article is licensed under a Creative Commons Attribution 4.0 International License, which permits use, sharing, adaptation, distribution and reproduction in any medium or format, as long as you give appropriate credit to the original author(s) and the source, provide a link to the Creative Commons licence, and indicate if changes were made. The images or other third party material in this article are included in the article's Creative Commons licence, unless indicated otherwise in a credit line to the material. If material is not included in the article's Creative Commons licence and your intended use is not permitted by statutory regulation or exceeds the permitted use, you will need to obtain permission directly from the copyright holder. To view a copy of this licence, visit http://creativecommons.org/licen ses/by/4.0\%.

\section{References}

Aguilar-Melo, A. R., Calmé, S., Smith-Aguilar, S. E., \& Ramos-Fernandez, G. (2018). Fission-fusion dynamics as a temporally and spatially flexible behavioral strategy in spider monkeys. Behavioral Ecology and Sociobiology, 72, 150. https://doi.org/10.1007/s00265-018-2562-y.

Aguilar-Melo, A. R., Calmé, S., Pinacho-Guendulain, B., Smith-Aguilar, S. E., \& Ramos-Fernández, G. (2020). Ecological and social determinants of association and proximity patterns in the fissionfusion society of spider monkeys (Ateles geoffroyi ). American Journal of Primatology, 82(1), e23077. https://doi.org/10.1002/ajp.23077.

Amrein, M., Heistermann, M., \& Weingrill, T. (2014). The effect of fission-fusion zoo housing on hormonal and behavioral indicators of stress in Bornean orangutans (Pongo pygmaeus). International Journal of Primatology, 35(2), 509-528. https://doi.org/10.1007/s10764-014-9765-5.

Andres, D., Clutton-Brock, T. H., Kruuk, L. E. B., Pemberton, J. M., Stopher, K. V., \& Ruckstuhl, K. E. (2013). Sex differences in the consequences of maternal loss in a long-lived mammal, the red deer (Cervus elaphus). Behavioral Ecology and Sociobiology, 67(8), 1249-1258. https://doi.org/ 10.1007/s00265-013-1552-3.

Arora, N., Nater, A., van Schaik, C. P., Willems, E. P., van Noordwijk, M. A., Goossens, B., et al (2010). Effects of Pleistocene glaciations and rivers on the population structure of Bornean orangutans (Pongo pygmaeus). Proceedings of the National Academy of Sciences, 107(50), 21376-21381. https://doi.org/10.1073/pnas.1010169107.

Arora, N., van Noordwijk, M. A., Ackermann, C., Willems, E. P., Nater, A., Greminger, M., ... Krützen, M. (2012). Parentage-based pedigree reconstruction reveals female matrilineal clusters and malebiased dispersal in nongregarious Asian great apes, the Bornean orang-utans (Pongo pygmaeus). Molecular Ecology, 21(13), 3352-3362. https://doi.org/10.1111/j.1365-294X.2012.05608.x

Ashbury. (2020). Movement and space-use among Bornean orangutans. Doctoral dissertation. University of Zurich.

Ashbury, A. M., Willems, E. P., Utami Atmoko, S. S., Saputra, F., van Schaik, C. P., \& van Noordwijk, M. A. (2020). Home range establishment and the mechanisms of philopatry among female Bornean orangutans (Pongo pygmaeus wurmbii) at Tuanan. Behavioral Ecology and Sociobiology, 74, 42. https://doi.org/10.1007/s00265-020-2818-1.

Baden, A. L., Webster, T. H., \& Kamilar, J. M. (2016). Resource seasonality and reproduction predict fission-fusion dynamics in black-and-white ruffed lemurs ( Varecia variegata ): ruffed lemur fission-fusion dynamics. American Journal of Primatology, 78(2), 256-279. https://doi.org/10.1002/ ajp. 22507.

Bastian, M. L., Zweifel, N., Vogel, E. R., Wich, S. A., \& van Schaik, C. P. (2010). Diet traditions in wild orangutans. American Journal of Physical Anthropology, 143(2), 175-187. https://doi.org/10.1002/ ajpa.21304. 
Bates, D., Maechler, M., Bolker, B., \& Walker, S. (2015). Fitting linear mixed-effects models using lme4. Journal of Statistical Software, 67(1), 1-48. https://doi.org/10.18637/jss.v067.i01.

Bond, M. L., Lee, D. E., Ozgul, A., \& König, B. (2019). Fission-fusion dynamics of a megaherbivore are driven by ecological, anthropogenic, temporal, and social factors. Oecologia, 191(2), 335-347. https://doi.org/10.1007/s00442-019-04485-y.

Brooks, M. E., Kristensen, K., van Benthem, K. J., Magnusson, A., Berg, C. W., Nielsen, A., Skaug, H. J., Maechler, M., \& Bolker, B. M. (2017). glmmTMB balances speed and flexibility among packages for zero-inflated generalized linear mixed modeling. The R Journal, 9(2), 378-400.

Byers, J. A., \& Walker, C. (1995). Refining the motor training hypothesis for the evolution of play. The American Naturalist, 146, 25-40.

Calder, W. J., Lifferth, G., Moritz, M. A., \& St Clair, S. B. (2010). Physiological effects of smoke exposure on deciduous and conifer tree species. International Journal of Forestry Research, 2010, 1-7. https://doi.org/10.1155/2010/438930.

Campbell-Smith, G., Campbell-Smith, M., Singleton, I., \& Linkie, M. (2011). Raiders of the lost bark: orangutan foraging strategies in a degraded landscape. PLoS One, 6(6), e20962. https://doi.org/10. 1371/journal.pone.0020962.

Cohen, J. (1988). Statistical power analysis for the behavioral sciences (2nd ed.). L. Erlbaum Associates.

Corlett, R. T., \& Lafrankie Jr., J. V. (1998). Potential impacts of climate change on tropical Asian forests through an influence on phenology. Climatic Change, 39(2/3), 439-453. https://doi.org/10.1023/A: 1005328124567.

Crockford, C., Samuni, L., Vigilant, L., \& Wittig, R. M. (2020). Postweaning maternal care increases male chimpanzee reproductive success. Science Advances, 6(38), eaaz5746. https://doi.org/10. 1126/sciadv.aaz5746.

Davies, S. J., \& Unam, L. (1999). Smoke-haze from the 1997 Indonesian forest fires: effects on pollution levels, local climate, atmospheric CO 2 concentrations, and tree photosynthesis. Forest Ecology and Management, 124, 137-144. https://doi.org/10.1016/S0378-1127(99)00060-2.

Doran, D. (1997). Influence of seasonality on activity patterns, feeding behavior, ranging, and grouping patterns in Tai chimpanzees. International Journal of Primatology, 18, 183-206.

Dunkel, L. P., Arora, N., van Noordwijk, M. A., Atmoko, S. S. U., Putra, A. P., Krützen, M., \& van Schaik, C. P. (2013). Variation in developmental arrest among male orangutans: A comparison between a Sumatran and a Bornean population. Frontiers in Zoology, 10(1), 12. https://doi.org/10. 1186/1742-9994-10-12.

Erb, W. M., Barrow, E. J., Hofner, A. N., Utami-Atmoko, S. S., \& Vogel, E. R. (2018). Wildfire smoke impacts activity and energetics of wild Bornean orangutans. Scientific Reports, 8, 7606. https://doi. org/10.1038/s41598-018-25847-1.

Fairbanks, L. A. (2000). The developmental timing of primate play: A neural selection model. In S. T. S. T. Parker, J. Langer, \& M. L. McKinney (Eds.), Biology, brains, and behavior: The evolution of human development (pp. 131-158). School of American Research Press.

Field, R. D., Van Der Werf, G. R., Fanin, F., Fetzer, E. J., Fuller, R., Jethva, H., ... Worden, H. M. (2016). Indonesian fire activity and smoke pollution in 2015 show persistent nonlinear sensitivity to El Niño-induced drought. PNAS, 113, 9204-9209. https://doi.org/10.1073/pnas.1524888113

Fröhlich, M., Kunz, J., Fryns, C., Falkner, S., Rukmana, E., Schuppli, M., et al (2020). Social interactions and interaction partners in infant orang-utans of two wild populations. Animal Behaviour, 166, 183-191. https://doi.org/10.1016/j.anbehav.2020.06.008.

Galdikas, B. M. F. (1985a). Subadult male orangutan sociality and reproductive behavior at Tanjung Puting. American Journal of Primatology, 8(2), 87-99.

Galdikas, B. M. F. (1985b). Orangutan sociality at Tanjung Puting. American Journal of Primatology, 9(2), 101-119. https://doi.org/10.1002/ajp.1350090204.

Galdikas, B. M. F. (1985c). Adult male sociality and reproductive tactics among orangutans at Tanjung Puting. Folia Primatologica, 45, 9-24.

Glauber, A. J., Moyer, S., Adriani, M., \& Gunawan, I. (2016). The cost of fire: an economic analysis of Indonesia's 2015 fire crisis, Indonesia sustainable landscapes knowledge, Note No. 1. World Bank.

Graham, K. L., \& Burghardt, G. M. (2010). Current perspectives on the biological study of play: signs of progress. The Quarterly Review of Biology, 85(4), 393-418.

Gwynn, A. L.(2020) The effects of forest fires on the behaviour and health of Bornean orang-utans in Sebangau peat-swamp forest. Master's Thesis, University of Exeter. 
Harrison, M. E., Morrogh-Bernard, H. C., \& Chivers, D. J. (2010). Orangutan energetics and the influence of fruit availability in the nonmasting peat-swamp forest of Sabangau, Indonesian Borneo. International Journal of Primatology, 31(4), 585-607. https://doi.org/10.1007/s10764-010-9415-5.

Harrison, M. E., Capilla, B. R., Thornton, S. A., Cattau, M. E., \& Page, S. E. (2016). Impacts of the 2015 fire season on peat-swamp forest biodiversity in Indonesian Borneo. 15th International Peat Congress 2016, pp 713-717.

Harrison, M. E., Nasir, D., Healy, W., Kulu, I. P., Husson, S. J., Santiano Purwanto, A., Iwan Page, S. E., van Veen, F., Imron, M. A. (2021). The importance of monitoring research in assessing impacts of anthropogenic activities on tropical peatland biodiversity: examples from Central Kalimantan, Indonesia. The $16^{\text {th }}$ International Peatland Congress; Tallinn 2021; Abstract Book. pp 44-50.

Heintz, M. R., Murray, C. M., Markham, A. C., Pusey, A. E., \& Lonsdorf, E. V. (2017). The relationship between social play and developmental milestones in wild chimpanzees (Pan troglodytes schweinfurthii). American Journal of Primatology, 79, e22716. https://doi.org/10.1002/ajp.22716.

Husson, S. J., Wich, S. A., Marshall, A. J., Dennis, R. D., Ancrenaz, M., Brassey, R., Gumal, M., Hearn, A. J., Meijaard, E., Simorangkir, T., \& Singleton, I. (2009). Orangutan distribution, density, abundance and impacts of disturbance. In S. A. Wich, S. S. Utami Atmoko, T. Mitra Setia, \& C. P. van Schaik (Eds.), Orangutans: geographic variation in behavioral ecology and conservation (pp. 77-96). Oxford University Press.

James, G., Witten, D., Hastie, T., \& Tibshirani, R. (2013). An introduction to statistical learning (Vol. 103). Springer. https://doi.org/10.1007/978-1-4614-7138-7.

Kiely, L., Spracklen, D. V., Wiedinmyer, C., Conibear, L., Reddington, C. L., Arnold, S. R., et al (2020). Air quality and health impacts of vegetation and peat fires in Equatorial Asia during 2004-2015. Environmental Research Letters, 15(9), 094054. https://doi.org/10.1088/1748-9326/ab9a6c.

Knott, C. D. (1998). Changes in orangutan caloric intake, energy balance, and ketones in response to fluctuating fruit availability. International Journal of Primatology, 19(6), 1061-1079.

Knott, C. D., Beaudrot, L., Snaith, T., White, S., Tschauner, H., \& Planasky, G. (2008). Female-female competition in Bornean orangutans. International Journal of Primatology, 29, 975-997. https:// doi.org/10.1007/s10764-008-9278-1.

Kobayashi, H., Matsunaga, T., \& Hoyano, A. (2005). Net primary production in Southeast Asia following a large reduction in photosynthetically active radiation owing to smoke. Geophysical Research Letters, 32, L02403. https://doi.org/10.1029/2004GL021704.

Koplitz, S. N., Mickley, L. J., Marlier, M. E., Buonocore, J. J., Kim, P. S., Liu, T., et al (2016). Public health impacts of the severe haze in Equatorial Asia in September-October 2015: demonstration of a new framework for informing fire management strategies to reduce downwind smoke exposure. Environmental Research Letters, 11(9), 094023. https://doi.org/10.1088/1748-9326/11/9/094023.

Krause, J., \& Ruxton, G. D. (2002). Living in Groups. OUP.

Kunz, J. A., Duvot, G. J., van Noordwijk, M. A., Willems, E. P., Townsend, M., Mardianah, N., et al (2021). The cost of associating with males for Bornean and Sumatran female orangutans: a hidden form of sexual conflict? Behavioral Ecology and Sociobiology, 75(1), 6. https://doi.org/10.1007/ s00265-020-02948-4.

Kuznetsova, A., Brockhoff, P. B., \& Christensen, R. H. B. (2017). lmerTest Package: Tests in Linear Mixed Effects Models. Journal of Statistical Software, 82(13), 1-26. https://doi.org/10.18637/jss. v082.i13.

Leighton, M. (1993). Modeling dietary selectivity by Bornean orangutans: Evidence for integration of multiple criteria in fruit selection. International Journal of Primatology, 14(2), 257-313. https:// doi.org/10.1007/BF02192635.

Lim, Y.-K., Kovach, R. M., Pawson, S., \& Vernieres, G. (2017). The 2015/16 El Niño event in context of the MERRA-2 reanalysis: a comparison of the tropical Pacific with 1982/83 and 1997/98. Journal of Climate, 30(13), 4819-4842. https://doi.org/10.1175/JCLI-D-16-0800.1.

Lohberger, S., Stängel, M., Atwood, E. C., \& Siegert, F. (2018). Spatial evaluation of Indonesia's 2015 fire-affected area and estimated carbon emissions using Sentinel-1. Global Change Biology, 24(2), 644-654. https://doi.org/10.1111/gcb.13841.

Lüdecke, D. (2018). ggeffects: tidy data frames of marginal effects from regression models. Journal of Open Source Software, 3(26), 772. https://doi.org/10.21105/joss.00772.

Lüdecke, D., Ben-Shachar, M. S., Patil, I., Waggoner, P., \& Makowski, D. (2020). Assessment of regression models performance. CRAN Available from https://easystats.github.io/performance/.

Mackinnon, J. (1974). The behaviour and ecology of wild orang-utans (Pongo pygmaeus). Animal Behaviour, 22(1), 3-74. https://doi.org/10.1016/S0003-3472(74)80054-0. 
Makowski, D., Ben-Shachar, M. S., Patil, I., \& Lüdecke, D. (2020). Automated results reporting as a practical tool to improve reproducibility and methodological best practices adoption. CRAN Available from https://github.com/easystats/report.

Marshall, A. J., \& Wrangham, R. W. (2007). Evolutionary consequences of fallback foods. International Journal of Primatology, 28, 1219-1235. https://doi.org/10.1007/s10764-007-9218-5.

Marshall, A. J., Farr, M. T., Beaudrot, L., Zipkin, E. F., Feilen, K. L., Bell, L. G., et al (2021). Biotic and abiotic drivers of dispersion dynamics in a large-bodied tropical vertebrate, the Western Bornean orangutan. Oecologia, 196(3), 707-721. https://doi.org/10.1007/s00442-021-04964-1.

Marzec, M. A., Kunz, J. A., Falkner, S., Utami Atmoko, S. S., Alavi, S. E., Moldawer, A. M., ... van Noordwijk, M. A. (2016). The dark side of the red ape: male-mediated lethal female competition in Bornean orangutans. Behavioural Ecology Sociobiology, 70, 459-466. https://doi.org/10.1007/ s00265-015-2053-3

Matsumoto-Oda, A., Hosaka, K., Huffman, M. A., \& Kawanaka, K. (1998). Factors affecting party size in chimpanzees of the Mahale mountains. International Journal of Primatology, 19, 999-1011.

Meijaard, E. (2018). Indonesia's fires in the $21^{\text {st }}$ century: Causes, culprits, impacts, perceptions, and solutions. In E. Quah \& T. S. Tan (Eds.), Pollution across borders: transboundary fire, smoke and haze in Southeast Asia (pp. 121-136). World Scientific Publishing.

Meric de Bellefon, J. (2017). Consequences of the forest fires for the diet, ranging behaviors, and social interactions of wild female Bornean orangutans (Pongo pygmaeus wurmbii). MSc Thesis. University of Zurich.

Miettinen, J., Shi, C., \& Liew, S. C. (2017). Fire distribution in peninsular Malaysia, Sumatra and Borneo in 2015 with special emphasis on peatland fires. Environmental Management, 60(4), 747-757. https://doi.org/10.1007/s00267-017-0911-7.

Mitra Setia, T., Delgado, R. A., Utami Atmoko, S. S., Singleton, I., \& van Schiak, C. P. (2009). Social organization and male-female relationships. In S. A. Wich, S. S. Utami Atmoko, T. Mitra Setia, \& C. P. van Schaik (Eds.), Orangutans: geographic variation in behavioral ecology and conservation. Oxford University Press.

Morrogh-Bernard, H., Husson, S. J., Knott, C. D., Wich, S. A., van Schaik, C. P., et al (2009). Orangutan activity budgets and diet. In S. A. Wich, S. S. Utami Atmoko, T. Mitra Setia, \& C. P. van Schaik (Eds.), Orangutans: geographic variation in behavioral ecology and conservation. Oxford University Press.

Morrogh-Bernard, H. C., Morf, N., Chivers, D. J., \& Krützen, M. (2011). Dispersal patterns of orangutans (Pongo spp.) in a Bornean peat-swamp forest. International Journal of Primatology, 32, 362-376. https://doi.org/10.1007/s10764-010-9474-7.

Murray, C., Lonsdorf, E., Stanton, M., Wellens, K., Millera, J., Goodall, J., \& Pusey, A. (2014). Early social exposure in wild chimpanzees: mothers with sons are more gregarious than mothers with daughters. Proceedings of the National Academy of Sciences, 111, 18189-18194. https://doi.org/ 10.1073/pnas.1409507111.

O’Connell, C. A., DiGiorgio, A. L., Ugarte, A. D., Brittain, R. S. A., Naumenko, D. J., Utami Atmoko, S. S., \& Vogel, E. R. (2021). Wild Bornean orangutans experience muscle catabolism during episodes of fruit scarcity. Scientific Reports, 11(1), 10185.

Overpeck, J. T., Rind, D., \& Goldberg, R. (1990). Climate-induced changes in forest disturbance and vegetation. Nature, 343(6253), 51-53. https://doi.org/10.1038/343051a0.

R Core Team (2020). R: A language and environment for statistical computing. R Foundation for Statistical Computing URL: https://www.R-project.org/. Accessed Jan 2021.

Radchuk, V., Reed, T., Teplitsky, C., van de Pol, M., Charmantier, A., Hassall, C., et al (2019). Adaptive responses of animals to climate change are most likely insufficient. Nature Communications, 10(1), 3109. https://doi.org/10.1038/s41467-019-10924-4.

Rayadin, Y., \& Spehar, S. N. (2015). Body mass of wild Bornean orangutans living in human-dominated landscapes: implications for understanding their ecology and conservation: body mass of Bornean orangutans. American Journal of Physical Anthropology, 157(2), 339-346. https://doi.org/10.1002/ ajpa.22709.

Roth, T. S., Rianti, P., Fredriksson, G. B., Wich, S. A., \& Nowak, M. G. (2020). Grouping behavior of Sumatran orangutans (Pongo abelii) and Tapanuli orangutans Pongo tapanuliensis living in forest with low fruit abundance. American Journal of Primatology, 2020, e23123. https://doi.org/10. 1002/ajp.23123.

RStudio Team (2020). RStudio: integrated development for R. RStudio, PBC URL http://www.rstudio. com/. Accessed Jan 2021. 
Russon, A. E., Wich, S. A., Ancrenaz, M., et al (2009). Geographic variation in orangutan diets. In S. A. Wich, S. S. Utami Atmoko, T. Mitra Setia, \& C. P. van Schaik (Eds.), Orangutans: geographic variation in behavioral ecology and conservation. Oxford University Press.

Russon, A. E., Kuncoro, P., \& Ferisa, A. (2015). Orangutan behavior in Kutai National Park after drought and fire damage: adjustments to short- and long-term natural forest regeneration. American Journal of Primatology, 77, 1276-1289. https://doi.org/10.1002/ajp.22480.

Samuni, L., Tkaczynski, P., Deschner, T., Löhrrich, T., Wittig, R. M., \& Crockford, C. (2020). Maternal effects on offspring growth indicate post-weaning juvenile dependence in chimpanzees (Pan troglodytes verus). Frontiers in Zoology, 17(1), 1. https://doi.org/10.1186/s12983-019-0343-8.

Schuppli, C., Meulman, E. J. M., Forss, S. I. F., Aprilinayati, F., van Noordwijk, M. A., \& van Schaik, C. P. (2016). Observational social learning and socially induced practice of routine skills in immature wild orang-utans. Animal Behaviour, 119, 87-98.

Schuppli, C., van Noordwijk, M., Atmoko, S. U., \& van Schaik, C. (2020). Early sociability fosters later exploratory tendency in wild immature orangutans. Science. Advances, 6(2), eaaw2685. https://doi. org/10.1126/sciadv.aaw2685.

Singleton, I., \& van Schaik, C. P. (2002). The Social Organisation of a Population of Sumatran OrangUtans. Folia Primatologica, 73(1), 1-20. https://doi.org/10.1159/000060415.

Singleton, I., Knott, C. D., Morrogh-Bernard, H. C., Wich, S. A., \& van Schaik, C. P. (2009). Ranging behavior of orangutan females and social organization. In S. A. Wich, S. S. Utami Atmoko, T. Mitra Setia, \& C. P. van Schaik (Eds.), Orangutans: geographic variation in behavioral ecology and conservation (pp. 245-253). Oxford University Press.

Smith, J. E., Kolowski, J. M., Graham, K. E., Dawes, S. E., \& Holekamp, K. E. (2008). Social and ecological determinants of fission-fusion dynamics in the spotted hyaena. Animal Behaviour, 76(3), 619-636. https://doi.org/10.1016/j.anbehav.2008.05.001.

Spillmann, B., Willems, E. P., van Noordwijk, M. A., Setia, T. M., \& van Schaik, C. P. (2017). Confrontational assessment in the roving male promiscuity mating system of the Bornean orangutan. Behavioral Ecology and Sociobiology, 71(1), 20. https://doi.org/10.1007/s00265-016-2252-6.

Stanton, M. A., Lonsdorf, E. V., Murray, C. M., \& Pusey, A. E. (2020). Consequences of maternal loss before and after weaning in male and female wild chimpanzees. Behavioral Ecology and Sociobiology, 74(2), 22. https://doi.org/10.1007/s00265-020-2804-7.

Sterck, E. H. M., Watts, D. P., \& van Schaik, C. P. (1997). The evolution of female social relationships in nonhuman primates. Behavioral Ecology and Sociobiology, 41(5), 291-309. https://doi.org/10. $1007 / \mathrm{s} 002650050390$.

Stiegler, C., Meijide, A., Fan, Y., Ashween Ali, A., June, T., \& Knohl, A. (2019). El Niño-Southern Oscillation (ENSO) event reduces $\mathrm{CO} 2$ uptake of an Indonesian oil palm plantation. Biogeosciences, 16, 2873-2890. https://doi.org/10.5194/bg-16-2873-2019.

Sueur, C., King, A. J., Conradt, L., Kerth, G., Lusseau, D., Mettke-Hofmann, C., et al (2011). Collective decision-making and fission-fusion dynamics: a conceptual framework. Oikos, 120(11), 16081617. https://doi.org/10.1111/j.1600-0706.2011.19685.x.

Sugardjito, J., te Boekhorst, I. J. A., \& van Hooff, J. A. R. A. M. (1987). Ecological constraints on the grouping of wild orang-utans (Pongo pygmaeus) in the Gunung Leuser National Park, Sumatra, Indonesia. International Journal of Primatology, 8(1), 17-41. https://doi.org/10.1007/BF027 37112.

Tacconi, L. (2016). Preventing fires and haze in Southeast Asia. Nature Climate Change, 6(7), 640-643. https://doi.org/10.1038/nclimate3008.

Te Boekhorst, I. J. A., Schürmann, C. L., \& Sugardjito, J. (1990). Residential status and seasonal movement of wild orang-utans in the Gunung Leuser Reserve (Sumatera, Indonesia). Animal Behaviour, 39, 1098-1109.

Tung, J., Archie, E. A., Altmann, J., \& Alberts, S. C. (2016). Cumulative early life adversity predicts longevity in wild baboons. Nature Communications, 7(1), 11181. https://doi.org/10.1038/ncomm s11181.

Utami Atmoko, S. S., Mitra Setia, T., Goossens, B., James, S. S., Knott, C. D., Morrogh-Bernard, H. C., et al (2009). Orangutan mating behaviour and strategies. In S. A. Wich, S. S. Utami Atmoko, T. Mitra Setia, \& C. P. van Schaik (Eds.), Orangutans: geographic variation in behavioral ecology and conservation (pp. 235-244). Oxford University Press.

van Leeuwen, E. J. C., Mulenga, I. C., \& Chidester, D. L. (2013). Early deprivation negatively affects social skill acquisition in chimpanzees (Pan troglodytes). Anumal Cognition, 17, 407-414. https:// doi.org/10.1007/s10071-013-0672-5. 
van Noordwijk, M. A. (2012). From maternal investment to lifetime maternal care. In J. C. Mitani, J. Call, P. M. Kappeler, R. A. Palombit, \& J. B. Silk (Eds.), The evolution of primate societies (pp. 321-342). The University of Chicago Press.

van Noordwijk, M. A., Sauren, S. E. B., Nuzuar Abulani, A., Morrogh-Bernard, H. C., Utami Atmoko, S. S., \& van Schaik, C. P. (2009). Development of independence: Sumatran and Bornean orangutans compared. In S. A. Wich, S. S. Utami Atmoko, T. Mitra Setia, \& C. P. van Schaik (Eds.), Orangutans: geographic variation in behavioral ecology and conservation (pp. 189-203). Oxford University Press.

van Noordwijk, M. A., Arora, N., Willems, E. P., Dunkel, L. P., Amda, R. N., Mardianah, N., ... van Schaik, C. P. (2012). Female philopatry and its social benefits among Bornean orangutans. Behavioral Ecology and Sociobiology, 66(6), 823-834. https://doi.org/10.1007/s00265-012-1330-7

van Noordwijk, M. A., Utami Atmoko, S. S., Knott, C. D., Kuze, N., Morrogh-Bernard, H. C., Oram, F., ... Willems, E. P. (2018). The slow ape: High infant survival and long interbirth intervals in wild orangutans. Journal of Human Evolution, 125, 38-49. https://doi.org/10.1016/j.jhevol.2018.09.004 van Schaik, C. P. (1999). The socioecology of fission-fusion sociality in orangutans. Primates, 40, 73-90. van Schaik, C. P., \& Brockman, D. K. (2005). Seasonality in primate ecology, reproduction, and life history: an overview. In D. K. Brockman \& C. P. van Schaik (Eds.), Seasonality in Primates (1st ed., pp. 3-20). Cambridge University Press. https://doi.org/10.1017/CBO9780511542343.002.

van Schaik, C. P., \& Pfannes, K. R. (2005). Tropical climates and phenology: a primate perspective. In D. K. Brockman \& C. P. van Schaik (Eds.), Seasonality in primates: studies of living and extinct human and non-human primates (pp. 23-54). Cambridge University Press.

van Schaik, C. P., \& Pradhan, G. R. (2003). A model for tool-use traditions in primates: implications for the coevolution of culture and cognition. Journal of Human Evolution, 44(6), 645-664. https://doi. org/10.1016/S0047-2484(03)00041-1.

van Schaik, C. P., Marshall, A. J., \& Wich, S. A. (2009). Geographic variation in orangutan behavior and biology. In S. A. Wich, S. S. Utami Atmoko, T. Mitra Setia, \& C. P. van Schaik (Eds.), Orangutans: geographic variation in behavioral ecology and conservation (pp. 351-361). Oxford University Press.

van Schaik, C. P., Wich, S. A., Utami, S. S., \& Odom, K. (2005). A simple alternative to line transects of nests for estimating orangutan densities. Primates, 46(4), 249-254. https://doi.org/10.1007/ s10329-005-0134-z.

Vogel, E. R., Haag, L., Mitra-Setia, T., van Schaik, C. P., \& Dominy, N. J. (2009). Foraging and ranging behavior during a fallback episode: Hylobates albibarbis and Pongo pygmaeus wurmbii compared. American Journal of Physical Anthropology, 140(4), 716-726. https://doi.org/10.1002/ajpa.21119.

Vogel, E. R., Knott, C. D., Crowley, B. E., Blakely, M. D., Larsen, M. D., \& Dominy, N. J. (2012). Bornean orangutans on the brink of protein bankruptcy. Biology Letters, 8(3), 333-336. https://doi.org/10.1098/ rsbl.2011.1040.

Vogel, E. R., Harrison, M. E., Zulfa, A., Bransford, T. D., Alavi, S. E., Husson, S., ... Farida, W. R. (2015). Nutritional differences between two orangutan habitats: implications for population density. PLoS One, 10(10), e0138612. https://doi.org/10.1371/journal.pone.0138612

Vogel, E. R., Alavi, S. E., Utami-Atmoko, S. S., van Noordwijk, M. A., Bransford, T. D., Erb, W. M., et al (2016). Nutritional ecology of wild Bornean orangutans ( Pongo pygmaeus wurmbii ) in a peat swamp habitat: effects of age, sex, and season. American Journal of Primatology, 79(4), e22618. https://doi.org/10.1002/ajp.22618.

Watts, H. E., Tanner, J. B., Lundrigan, B. L., \& Holekamp, K. E. (2009). Post-weaning maternal effects and the evolution of female dominance in the spotted hyena. Proceedings of the Royal Society B: Biological Sciences, 276(1665), 2291-2298. https://doi.org/10.1098/rspb.2009.0268.

Wellens, K. R. (2018). Social Behavior in Wild Male Chimpanzees: Development and Maternal Relationships. (PhD), George Washington University, Washington DC.

Wich, S., Utami Atmoko, S., Mitra Setia, T., Djoyosudharmo, S., \& Geurts, M. (2006). Dietary and energetic responses of Pongo abelii to fruit availability fluctuations. International Journal of Primatology, 27, 1535-1550.

Wickham, H. (2016). ggplot2: elegant graphics for data analysis. Springer.

Wilke, C. O. (2020). cowplot: streamlined plot theme and plot annotations for 'ggplot2'. R package version 1.1.1. https://CRAN.R-project.org/package=cowplot. Accessed Jan 2021.

Wolfe, N. D., Karesh, W. B., Kilbourn, A. M., Cox-Singh, J., Bosi, E. J., Rahman, H. A., et al (2002). The impact of ecological conditions on the prevalence of malaria among orangutans. Vector Borne and Zoonotic Diseases, 2(2), 97-103. https://doi.org/10.1089/153036602321131896. 
Wright, S. J., \& van Schaik, C. P. (1994). Light and the phenology of tropical trees. American Naturalist, 143, 192-199.

Young, T., \& Isbell, L. (2002). Ecological models of female social relationships in primates: similarities, disparities, and some directions for future clarity. Behaviour, 139(2), 177-202. https://doi.org/10. $1163 / 156853902760102645$.

\section{Authors and Affiliations}

Alison M. Ashbury ${ }^{1,2,3}$ (D) Jade Meric de Bellefon ${ }^{1} \cdot J^{\text {Julia A. Kunz }}{ }^{1}$. Misdi Abdullah ${ }^{4}$ Anna M. Marzec ${ }^{1}$ - Caroline Fryns ${ }^{1,5}$. Sri Suci Utami Atmoko ${ }^{4}$. Carel P. van Schaik ${ }^{1,6,7}$. Maria A. van Noordwijk $k^{1,7}$

$\triangle$ Alison M. Ashbury aashbury@ab.mpg.de

1 Department of Anthropology, University of Zurich, Zurich, Switzerland

2 Present Address: Department of Biology, University of Konstanz, Konstanz, Germany

3 Present Address: Department for the Ecology of Animal Societies, Max Planck Institute for Animal Behavior, Konstanz, Germany

4 Fakultas Biologi, Universitas Nasional, Jakarta, Indonesia

5 Present Address: Institut de Biologie, Université de Neuchâtel, Neuchâtel, Switzerland

6 Department of Evolutionary Biology and Environmental Sciences, University of Zurich, Zurich, Switzerland

7 Comparative Socioecology Group, Max Planck Institute for Animal Behavior, Konstanz, Germany 